\title{
Emotional harm from disrespect: the neglected preventable harm
}

\author{
Lauge Sokol-Hessner, ${ }^{1}$ Patricia Henry Folcarelli, ${ }^{2}$ Kenneth E F Sands ${ }^{2}$
}

\begin{abstract}
${ }^{1}$ Medicine and Health Care Quality, Beth Israel Deaconess Medical Center, Boston, Massachusetts, USA

${ }^{2}$ Health Care Quality, Beth Israel Deaconess Medical Center, Boston, Massachusetts, USA
\end{abstract}

\section{Correspondence to}

Dr Lauge Sokol-Hessner, Medicine and Health Care Quality, W/PBS-2, Beth Israel Deaconess Medical Center, Boston, MA 02215, USA; Ihessner@bidmc.harvard.edu

Received 3 February 2015 Revised 25 May 2015 Accepted 30 May 2015 Published Online First 17 June 2015

\section{INTRODUCTION}

Consider these actual patient experiences:

- A patient is admitted to the hospital for a bowel obstruction from a known malignancy. She calls her cancer specialist about this complication, but he is unavailable. A covering provider reading from her file says 'your cancer is untreatable'. This is the first time she has heard this.

- A patient dies in the hospital and the next day the funeral home collects a body from the hospital morgue. After embalming the body, the funeral home is notified by the hospital that they were given the wrong body. Because of this error, it may not be possible to process the correct body in time for the wake the following day.

Despite being simultaneously dreadful and familiar to healthcare professionals, ${ }^{1}$ cases like these are not systematically identified or addressed in hospital quality improvement programmes. ${ }^{2}$ As a result, we have no good way of preventing them and patients inevitably continue to suffer from these unnecessary emotional harms. These cases are examples of preventable harm that are deserving of formal capture, classification and action by the healthcare system.

The 1999 Institute of Medicine (IOM) Report To Err is Human found that existing definitions and systems for preventing harm were inadequate and recommended urgent, decisive steps to raise 'standards and expectations for improvements in safety'.3 Since then our ability to define, measure and prevent patient harm has improved substantially. For instance, in 1999, central line-associated bloodstream infections were considered unfortunate, but expected complications. Today they are commonly prevented, saving many lives. ${ }^{4}$

To date, the patient safety movement has focused primarily on physical injury, but definitions of harm in healthcare are much broader: ${ }^{5}$ any 'outcome that negatively affects the patient's health and/or quality of life'. ${ }^{6}$ When asked about consequences of adverse events, patients emphasise emotional harm more than physical harm. ${ }^{7}$ Emotional harms can erode trust, leave patients feeling violated and damage patient-provider relationships. ${ }^{8}{ }^{9}$ Such injuries can be severe and long lasting, with adverse effects on physical health. ${ }^{10}$ Failures to acknowledge and systematically address these harms ensure that they continue.

For these emotional harms, we are where we were with patient safety before 1999: we know they occur, but lacking a systematic approach to capture, categorise or assess them, we struggle to understand root causes and prevent future events. We do not even have reliable estimates of how often such harms occur. Some evidence suggests they may be more prevalent than physical harms. ${ }^{7} 11$

Undoubtedly, some of these events are preventable. The costs of failing to prevent them-both financial and otherwise-are unjustifiable. As the IOM Report states, 'it is simply not acceptable for patients to be harmed by the same health care system that is supposed to offer healing and comfort'. ${ }^{3}$

To focus our institution on these harms, we convened a multidisciplinary group which met regularly over the course of a year. The group included representation from healthcare quality, patient safety, risk management, performance assessment and regulatory compliance, ethics, social work, palliative care, communications, interpreter services, community relations, patient relations, hospital governance and our Patient Family Advisory Council. In this article, we describe how we have conceptualised these harms within the existing preventable harm framework, and we outline areas of future work.

\section{DEFINING EMOTIONAL HARM IN TERMS OF DIGNITY AND RESPECT}

Emotional harms can be conceptualised as harms to a patient's 'dignity' which 
can be caused by a failure to demonstrate adequate 'respect' for the patient as a person. The definitions of dignity and respect we use must allow us both to identify cases of harm, and to analyse them in ways that could lead to concrete steps to prevent them. Building from the extensive literature on dignity and respect in healthcare, dignity can be defined as the intrinsic, unconditional value of all human beings that makes them worthy of respect. ${ }^{12}{ }^{13}$ Respect can be defined as the sum of the actions we take to protect, preserve and enhance the dignity of our patients. It is our ethical obligation to show respect to all patients, at all times. ${ }^{14}$

Emotional harm is not always a consequence of someone's failure to demonstrate respect. The disease process itself can cause harm. A patient may feel that having a colostomy bag after cancer surgery is 'harmful' to her dignity, even if she was treated with the best medical care and utmost respect. The design of the healthcare system may also facilitate harm to dignity. For instance, architectural features of hospitals - such as semi-private rooms that lack privacy-may contribute to the violation a patient feels when he realises that others have overheard a conversation about sensitive issues.

\section{CAPTURING HARM EVENTS}

Databases of patient-generated and family-generated feedback, complaints and grievances, as well as adverse event reports from providers, are available in all US hospitals and can be used to capture reports of emotional harm. However, these data likely significantly under-represent the total burden of emotional harm. Because of the historical neglect of these harms, there has been limited awareness or expectation that emotional harm matters. Consequently, few providers currently report these types of events, and furthermore, as with physical harms, many patients and families may be hesitant to report them. Those who are most vulnerable-including those who are frail, from socioeconomically disadvantaged groups, or with limited English proficiency-may be particularly reticent. ${ }^{7}{ }^{8}$ As with efforts to prevent physical harms, institutions should encourage reporting of emotional harm by educating patients, families and providers. Such reporting facilitates institutional learning by identifying opportunities for improvement and informs efforts to prevent future harm. In addition, institutions should ensure that the response to reporting is fair and just, and develop systematic approaches to mitigating the guilt and isolation that accompany harm events and impede reporting. ${ }^{15}$

\section{CATEGORISING EVENTS AND IDENTIFYING STANDARDS OF RESPECT}

Categorising these harm events is a prerequisite to learning how to prevent them. Defining the specific components of harm to dignity in healthcare is difficult, especially in culturally diverse settings. It is easier to identify the behaviours or events that patients experienced as disrespectful that were associated with emotional harm. This patient-centred approach should acknowledge that those involved in the behaviours or events most likely did not intend them to be disrespectful. An advantage of using categories defined by behaviours or events is that it focuses on the potential opportunities for improvement.

All US healthcare organisations have internal policies and external regulations that define standards for many categories of respect. In 1972, our institution began distributing to patients a document articulating 'Your Rights as a Patient'. It is now a Joint Commission accreditation requirement that hospitals inform every patient about his/her rights. ${ }^{16}$ The Joint Commission and the Centers for Medicare and Medicaid Services have numerous additional policies articulating standards of respect. Additional guidance may be found in patient-centred and family-centred care resources. ${ }^{17}$ Future work should identify the prevalence of types of disrespect, as well as specific respectful behaviours that are most effective in preventing emotional harm.

\section{ASSESSING SEVERITY}

Methods of assessing the severity of emotional harm events should acknowledge that patients, families and providers may each rate the severity of harm differently. Initially, focusing on those cases where all parties agree that the harm was severe leverages the power of consensus, and may be most constructive. Analogous to the National Quality Forum's perspective on Serious Reportable Events such as wrong site surgery, ${ }^{18}$ some forms of disrespect should never occur. For instance, we have categorised the second case we described about body mismanagement after death as a 'never event'. Other forms of disrespect are not as egregious, and prioritising efforts to address them will depend on their frequency and their severity. Future work should define methods of assessing emotional harm severity that are transparent and reproducible.

\section{ACCOUNTABILITY}

As with physical harm, accountability for preventing emotional harms rests both with front-line providers and leaders. We assume that providers want to be respectful towards their patients. Positive examples should be celebrated and used to identify effective ways of being respectful. Aetiologies of a provider's lack of respect likely include a complex set of factors, including under appreciation for the context of patients' experiences, a lack of training, the effects of a stressful work environment and workload and a lack of support for respectful behaviour from peers, superiors or systems of care. ${ }^{9}$ While individual providers 
must take responsibility for their actions, initiatives to ensure respectful care must acknowledge and address these system factors.

Leaders must take responsibility for addressing the organisational contexts within which harms occur. Identifying and tracking the contributions of system factors to episodes of disrespect can provide leaders with the information they need to make improvements. ${ }^{9}$ In addition, a reliable culture of respect for patients almost certainly requires a culture of respect among organisational leaders and staff. Leaders must show respect for staff and providers by ensuring that staffing matches workload, eliminating waste from workflows, providing feedback and educational opportunities, modelling constructive responses to negative feedback and ensuring that evaluations of reports of disrespect use a just and fair process. Since respect is central to effective patient-provider relationships, ${ }^{9}$ as well as safe high-reliability healthcare organisations, ${ }^{19}$ efforts to improve organisational cultures of respect are likely to have broad positive effects. Public reporting may accelerate these improvements. ${ }^{20}$

\section{WHAT SHOULD WE DO WITH THESE CASES?}

Reports of emotional harm can be investigated using existing processes for physical harm. For instance, after learning of and verifying the terminal cancer case mentioned above, the patient relations representative should $\log$ it in the adverse event reporting system and categorise it as an example of 'disrespectful communication'. The harm is severe because of its irreversibility, permanence and the degree to which the care was contrary to contemporary community standards. In addition, our hospital's Patient's Rights policy informs patients that 'You are entitled to know fully about [your] diagnosis and treatment.... and your likely future medical course and prognosis...'

Investigations-including, where appropriate, root cause analyses-should be conducted to identify why specific emotional harms have occurred and how their recurrence can be prevented. As with physical harms, our early experience with emotional harms is that they are often the result of multiple failures. In this case, contributing factors could include the provider's knowledge, skills and attitudes, and also the work environment, information technology (IT) systems and care team communication. As we gain experience, we will be able to determine whether alternatives to root cause analysis would be more suitable. Once these analyses are performed, the case should enter a just and fair process of broader review through existing institutional committees. If it is determined that this case indeed represents preventable harm, corrective actions could include individual provider education and modifications to the work environment and IT systems to improve the reliability of advance care planning. All severe preventable emotional harms should be reported on a publicly-available harm dashboard.

\section{CONCLUSIONS}

Ensuring that our profession does not cause preventable harm to our patients requires that we address emotional harms with the same rigor we have applied to physical harms. To improve our accountability for established standards of respect, we must build consensus about the best methods of harm event capture, categorisation, severity assessment, investigation and corrective action. There are many challenges in this work, including establishing operational definitions of 'respect' across culturally diverse patient populations, recognising the contributions of system factors, focusing on learning rather than judging, supporting providers so they can improve, and identifying and implementing efficient and effective ways of ensuring respect. Overcoming these challenges should become our mission as we fulfil our fundamental ethical responsibility to 'do no harm'.

Acknowledgements Members of the Beth Israel Deaconess Medical Center Respect and Dignity workgroup include Erica Dente, Jane Foley, R.N., B.S.N., M.H.A., Lachlan Forrow, M.D., Harvey Freishtat, J.D., Shari Gold-Gomez, B.A., M.B.A., Jennifer Greene, M.S., Nancy Kasen, M.S., Lynn G Mackinson, R.N., M.S., C.C.R.N., Kathleen Murray, B.S., Stephen O’Neill, L.I.C.S.W., B.C.D., J.D., Barbara Sarnoff Lee, L.I.C.S.W., and

Melinda B. Van Niel, M.B.A., C.P.H.R.M. We thank Tom Delbanco, M.D. and James B Conway, M.B.A. for their important comments.

Contributors LS-H, PHF and KEFS all contributed to the concept, drafting and critical revision of the manuscript. Permission was obtained from all coauthors and acknowledged contributors to submit the manuscript including their names.

Funding Supported in part by a grant from the Gordon and Betty Moore Foundation.

Competing interests None declared.

Patient consent Obtained.

Provenance and peer review Not commissioned; externally peer reviewed.

\section{REFERENCES}

1 Francis R. The Mid Staffordshire NHS Foundation Trust Inquiry -Independent Inquiry into care provided by Mid Staffordshire NHS Foundation Trust-January 2005-March 2009-Volume I. London: The Stationery Office, 2010. http://webarchive. nationalarchives.gov.uk/20130107105354/http://www.dh.gov. uk/prod_consum_dh/groups/dh_digitalassets/@dh/@en/@ps/ documents/digitalasset/dh_113447.pdf (accessed 5 May 2015).

2 Lee TH. The word that shall not be spoken. N Engl J Med 2013;369:1777-9.

3 Institute of Medicine. To err is human: building a safer health system. Washington DC: National Academy Press, 2000.

4 Chopra V, Krein SL, Olmsted RN, et al. Prevention of Central Line-Associated Bloodstream Infections: Brief Update Review. Published Online First: March 2013. http://www.ncbi.nlm.nih. gov/books/NBK133364/ (accessed 21 Aug 2014).

5 World Health Organization. The Conceptual Framework for the International Classification for Patient Safety: Chapter 3Concepts and Preferred Terms. 2009. http://www.who.int/ patientsafety/taxonomy/icps_chapter3.pdf (accessed 8 Nov 2014). 
6 Governance for Quality and Patient Safety Steering Committee. Effective governance for quality and patient safety: a toolkit for healthcare board members and senior leaders: glossary of terms. Edmonton, AB: Canadian Patient Safety Institute, 2010. http:// www.patientsafetyinstitute.ca/English/toolsResources/ GovernancePatientSafety/Documents/PDF\%20of\%20Contents/ Glossary\%20of\%20Terms.pdf (accessed 8 Nov 2014).

7 Massó Guijarro P, Aranaz Andrés JM, Mira JJ, et al. Adverse events in hospitals: the patient's point of view. Qual Saf Health Care 2010;19:144-7.

8 Johnstone M-J, Kanitsaki O. The neglect of racism as an ethical issue in health care. J Immigr Minor Health 2010;12:489-95.

9 Leape LL, Shore MF, Dienstag JL, et al. Perspective: a culture of respect, part 1: the nature and causes of disrespectful behavior by physicians. Acad Med 2012;87:845-52.

10 Entwistle VA. Hurtful comments are harmful comments: respectful communication is not just an optional extra in healthcare. Health Expect 2008;11:319-20.

11 Kuzel AJ, Woolf SH, Gilchrist VJ, et al. Patient reports of preventable problems and harms in primary health care. Ann Fam Med 2004;2:333-40.

12 Dresser R. Chapter 19: Human dignity and the seriously ill patient. In: Human dignity and bioethics: essays commissioned by the president's council on bioethics. Washington DC, 2008. https://bioethicsarchive.georgetown.edu/pcbe/reports/human dignity/chapter19.html (accessed 9 Dec 2014).

13 UNESCO, 2011. Casebook on Human Dignity and Human Rights, Bioethics Core Curriculum Casebook Series, No. 1, UNESCO: Paris, 144 pp.

14 Beach MC, Duggan PS, Cassel CK, et al. What does "respect" mean? Exploring the moral obligation of health professionals to respect patients. J Gen Intern Med 2007;22:692-5.

15 Delbanco T, Bell SK. Guilty, afraid, and alone-struggling with medical error. N Engl J Med 2007;357:1682-3.

16 The Joint Commission. Comprehensive Accreditation Manual for Hospitals: Rights and Responsibilities of the Individual: Standard RI.01.01.01. Oak Brook, IL: Joint Commission Resources, 2015.

17 Institute for Patient- and Family-Centered Care. Patient- and Family-Centered Care: Core Concepts. http://www.ipfcc.org/ pdf/CoreConcepts.pdf (accessed 8 Nov 2014).

18 National Quality Forum (NQF). Serious reportable events in healthcare-2011 update: a consensus report. Washington DC: NQF, 2011.

19 Leape LL, Shore MF, Dienstag JL, et al. Perspective: a culture of respect, part 2: creating a culture of respect. Acad Med 2012;87:853-8.

20 Pronovost PJ. Learning accountability for patient outcomes. JAMA 2010;304:204-5. 